\title{
Assessment of Climate and Land Use Change Projections and their Impacts on Flooding
}

\author{
Emmanuel Rukundo, Ahmet Doğan* \\ Yildiz Technical University, Department of Civil Engineering, Istanbul, Turkey
}

Received: 24 March 2016

Accepted: 20 June 2016

\begin{abstract}
The increase in extreme flooding in urban areas has sparked research interest in the quantitative impact of climate and land use change on flooding in cities. This article presents the results of a study that evaluated climate change and urbanization effects on flood hydrographs. General circulation models (GCMs) were applied to determine global climate change in the coming 100 years depending on various developmental trends and global greenhouse gas emission scenarios. A statistical downscaling methodology was applied on GCMs to generate local future climate data at high resolution. The Future projections of land use change data were combined together with the climate change predictions data and inserted into a hydrological model in order to estimate peak flood discharge rates at Kigali city in Rwanda for considered scenarios. The outcomes of the study show that the downscaled mean annual rainfall indicates neither systematic increments nor decrements in the next 100 years. The hydrological modeling results show the considerable impact of climate change by decreasing the expected flood peaks, whereas the land use change will cause a significant increase in floods. The land use change impacts predominate the climate change impacts at overall evaluation of floods.
\end{abstract}

Keywords: Climate change, land use change, flood, GSM Model, SDSM

\section{Introduction}

Climate and land use change have a significant impact on urban flooding and threaten the achievement of the development goals of modern cities. Floods are caused by hydro-meteorological phenomena and anthropogenic activities, of which later can be classified as land use change effects and the former can be categorized as climate change effects [1]. The change of climate has been predicted to increase extreme rainfall events [2]. The global average temperature has increased by $0.85^{\circ} \mathrm{C}\left(0.65-1.06^{\circ} \mathrm{C}\right)$ over the period $1800-2012$ [3], and

*e-mail: ahmet@yildiz.edu.tr
$0.74 \pm 0.18^{\circ} \mathrm{C}$ over the period of $1906-2005$ [4]. These changes mostly have led to a vigorous hydrological cycle and in return it affects water resource availability, runoff patterns, and discharge regime of rivers and in some regions causes floods - especially in urban areas. As a result of the anthropogenic effects in cities such as the increase of impervious surfaces, the infiltration capacity in urban areas decreases and the risk of flash floods increases. Urbanization, by its nature, gives rise to the built up surfaces that in return increase the flow of rainwater and reduce of peak time of flood hydrographs.

General circulation models (GCMs) are useful tools to simulate the response of global warming and climate change by considering the increase of $\mathrm{CO}_{2}$ concentration in the atmosphere [4]. However, the GCMs' coarse 
resolutions (100-500 km) reduce their applicability where regional scales are concerned [5]. Regional/local scales require high resolution to adequately represent complex topographical features when the environmental and hydrological impacts of climate change are to be examined [5]. In the last two decades, the statistical and dynamic downscaling models have been developed with the main aim of downscaling temporal and spatial outputs of GCMS at regional $(50 \times 50 \mathrm{~km})$ and local $(0-50 \mathrm{~km})$ levels [6-7]. The statistical downscaling model has been widely used in climate change studies [8-10]. Gebremeskel et al. (2005) [11] conducted a study on the analysis of the climate change effect on river flow by applying statistically downscaled global circulation scenarios in Alzette catchment in Luxembourg, where they found a significant increase in magnitude and frequency of future flooding in the basin. Wang et al. (2012) [10] presented a study on statistical downscaling of extreme precipitation and temperature as well as on the construction of future scenarios in an elevated cold zone. In their study, they used a statistical downscaling model to present future projections of extremes of daily precipitation and temperature, under different future scenarios in the Yellow River basin. Mahmood and Babel (2013) [6] presented a study on the assessment of the statistical downscaling model applied in Jhelum watershed in India and Pakistan for downscaling rainfall and temperature. Their results showed that catchment climate will be warmer and wetter compared to the base time. Cheng et al. (2012) [12] studied the potential effects of climate change on severe weather occurrences in Canada and found that the frequency and intensity of upcoming severe climate events will be getting remarkably larger over the studied area.

The Hydrologic Engineering Center - Hydrologic Modeling System (HEC-HMS) [13] has been applied for developing the rainfall-runoff relationship and estimating the flood discharge peak and volume. The model contains various hydrologic analysis procedures, including infiltration events and flood hydrographs. HEC-HMS has been widely used in numerous studies. Yener et al. (2007) [14] applied HEC-HMS to generate flood hydrographs in Yuvacik Basin, Turkey. Chu et al. (2009) [15] conducted a study on an event and continuous hydrologic modeling where HEC HMS was used for simulating surface runoff in the event, and continuous models in Mona Lake catchment of Michigan. Munyaneza et al. (2014) [16] used HEC-HMS to assess the availability of surface water in the Migina Basin and compared the model results to the results of tracer studies in terms of runoff components.

The purpose of this assessment is to simulate the rainfall under two of the IPCC SRES emissions by using the Hadley center coupled model [4] and to estimate the flood peak discharge under climate and land use change scenarios. This model was developed under A2 and B2 SRES emission scenarios in which A2 stands for mediumhigh emissions characterized by regional oriented economic development and high population growth, and B2 stands for medium-low emissions characterized by a world in which the emphasis is on local solutions to economic, social, and environmental sustainability. The former model is called HadCM3A2 and the latter is HadCM3B2 (where " 3 " states the version of the model while the last two characters - "A2" or "B2" - state the scenarios). These models assess the climate change impact by using statistical downscaling techniques. The adopted methodology was successfully applied to Kigali, Rwanda, which faces the typical challenge of climate variability, climate change, and land use change due to urbanization where flash floods during the rainy season have become a serious issue. The flood event of 2013 caused property damage and took the lives of four people.

\section{Material and Methods}

\section{Study Area}

The flood-sensitive area of Kigali is located near the outlet of Nyabugogo watershed in central-eastern Rwanda. Nyabugogo watershed covers both Kigali and rural areas. It extends between $2^{\circ} 00^{\prime}-1^{\circ} 45^{\prime} \mathrm{S}$ latitude and $29^{\circ} 50^{\prime}-30^{\circ} 35^{\prime} \mathrm{E}$ longitude, and the elevation ranges from 1,376 to 2,311 $\mathrm{m}$ above mean sea level (Fig. 1). The total area of Nyabugogo catchment is about $1,647 \mathrm{~km}^{2}$. The main land use activity in the basin is agriculture, which occupies about $897 \mathrm{~km}^{2}$ (about 54\%) of the basin. The Nyabugogo River crosses the Kigali and it is fed by tributaries from the urbanized part of Kigali such as the Rwanzekuma, Ruganwa, Mpazi, and Yanze rivers. Its estimated population is about 1.14 million. The climate of the region is mostly of temperate and equatorial type with the range of yearly average temperature for the period of 1970 to 2014 between $16^{\circ} \mathrm{C}$ and $23^{\circ} \mathrm{C}$ (depending on the altitude), and the calculated mean annual rainfall for the same period is about $995 \mathrm{~mm} \cdot \mathrm{year}^{-1}$.

\section{Flooding Situation in Kigali}

Kigali continues to be prone to flooding and floods have become a normal part of life during the rainy season

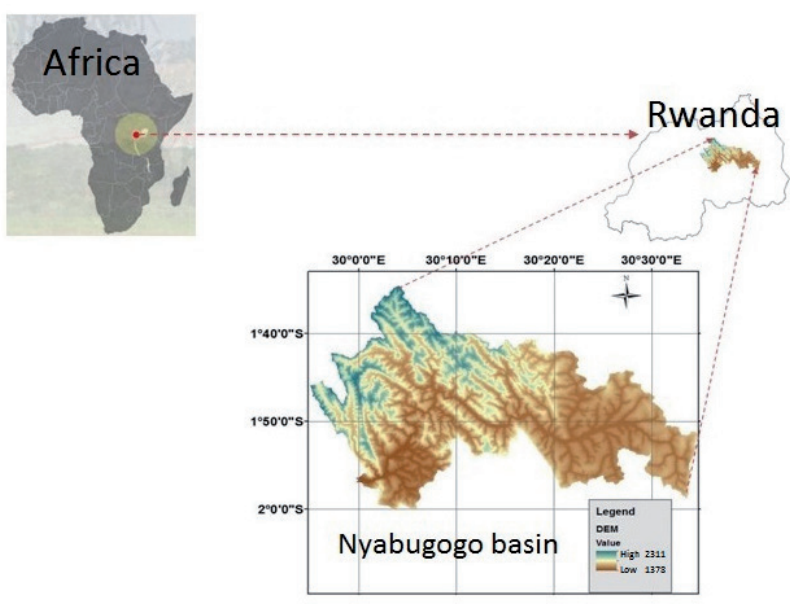

Fig. 1. The case study location. 
from April to June and September to December. Floods have been observed in Kigali since the 1960s, and their frequency has significantly increased over time with considerable adverse effects on human activities and the environment. The flooded zone of Kigali is nearly located to the outlet of Nyabugogo catchment and the floodprone zones of the city where different business activities take place. Generally, the floods in this area are mostly influenced by two factors: 1) the faulty and inadequate drainage capacity of the Nyabugogo during heavy rains and 2) the topography of Kigali, which is dominated by hills with steep slopes (up to $50 \%$ ) that dramatically increase runoff water during rainfall. Serious floods happen when heavy rainfall occurs, resulting in the rise of water levels of the Nyabugogo to its extreme values. Also, an inadequate land use practice such as constructing impervious layers (i.e., rooftops, roads, pavements, etc.) in the Nyabugogo flood zones plays a great role to the impact of flooding in this area.

\section{Climate Data}

The historical rainfall data for Kigali airport station, which is located near a flooded area $\left(01^{\circ} 58^{\prime} \mathrm{S}-30^{\circ} 08^{\prime} \mathrm{E}\right.$, elevation $1,490.0 \mathrm{~m}$ ) was collected from the Rwandan Ministry of Natural Resources (MINIRENA) and METEO-RWANDA, which are in charge of measuring, analyzing, and storing hydro meteorological data and forecasting the weather in Rwanda. The data used for downscaling GCM consists of the daily rainfall data for a period of 1961-2000. This period of data collection was selected according to the method that has been used during this research of the statistical downscaling model, which considers the calibration baseline of data in the period of 1961-1990 and its validation in 1991-2000.

The two types of daily predictor data required for this study were obtained from the Canadian Institute of Climate Studies website [17]: (a) the 26 predictors of the National Center of Environmental Prediction (NCEP) for 1961-2014 and (b) the 26 predictors of HadCM3 for A2 and B2 Scenarios for 1961-2099. These datasets were specially processed for the statistical downscaling model (SDSM). During preparation, the NCEP predictors $\left(2.5^{\circ} \times 2.5^{\circ}\right)$ were first interpolated to the grid resolution of HadCM3 $\left(2.5^{\circ} \times 3.75^{\circ}\right)$ to eliminate the spatial mismatch. Then, the NCEP and HadCM3 predictors were normalized with the mean and standard deviation obtained by the baseline period of 1961-1990 [18].

\section{Land Use Data}

The current and projected land use data were collected from the Kigali master plan conception as it shows clearly how the city is developing in terms of built-up (residential, commercial, industrial, social, and government infrastructure), water bodies, and agriculture (pervious area) (Table 1). The Kigali master plan provides a longterm vision for the city and it sets up fundamental pillars of sustainable urban development, such as protection
Table1. Current and proposed land use distribution in Kigali .

\begin{tabular}{|c|c|c|c|c|}
\hline \multirow{2}{*}{ Landuse Types } & \multicolumn{2}{|c|}{$\begin{array}{c}\text { Current land use } \\
(2012)\end{array}$} & \multicolumn{2}{c|}{$\begin{array}{c}\text { Proposed land } \\
\text { use }(2040)\end{array}$} \\
\cline { 2 - 5 } & $\begin{array}{c}\text { Area } \\
\left(\mathrm{km}^{2}\right)\end{array}$ & $\begin{array}{c}\text { Percent } \\
(\%)\end{array}$ & $\begin{array}{c}\text { Area } \\
\left(\mathrm{km}^{2}\right)\end{array}$ & $\begin{array}{c}\text { Percent } \\
(\%)\end{array}$ \\
\hline Residential & 67.58 & 9.24 & 152.16 & 20.8 \\
\hline Commercial & 2.85 & 0.39 & 8.78 & 1.2 \\
\hline Mixed use & 0.22 & 0.03 & 1.46 & 0.2 \\
\hline Public facilities & 13.74 & 1.88 & 14.63 & 2 \\
\hline Industry & 4.41 & 0.6 & 13.17 & 1.8 \\
\hline Natural area & 141.98 & 19.41 & 285.30 & 39 \\
\hline Agriculture & 461.37 & 63.07 & 116.31 & 15.9 \\
\hline Open space & 2.171 & 0.3 & 91.44 & 12.5 \\
\hline Water bodies & 2.905 & 0.4 & 1.46 & 0.2 \\
\hline Infrastructure/Roads & 20.84 & 2.85 & 30.72 & 4.2 \\
\hline Special use & 13.46 & 1.84 & 16.09 & 2.2 \\
\hline Total area & 731.53 & 100 & 731.53 & 100 \\
\hline
\end{tabular}

of wetlands, slopes, and forest areas. The current land use typology of Kigali is grouped into urban and rural clusters (Fig. 2). The total area occupied by urban areas is estimated to be $17 \%\left(124.27 \mathrm{~km}^{2}\right)$, whereas the rural portion dominates with $83 \%\left(606.73 \mathrm{~km}^{2}\right)$. The city is provided with many growth opportunities in terms of available undeveloped land and low-density areas with the potential to be developed. The city's current land use is dominated by agriculture $(63.10 \%)$, natural areas (19.40), and residential areas (9.20\%) (Fig. 3a), whereas the projected future land use distributions for 2040 will be dominated by residential (43\%), open and natural areas $(26 \%)$, industry $(5 \%)$, and commercial and mixed use (3\%) (Fig. 3b). This study took into account the master plan of Kigali, which is currently being implemented for assessing the land use change impact on the city.
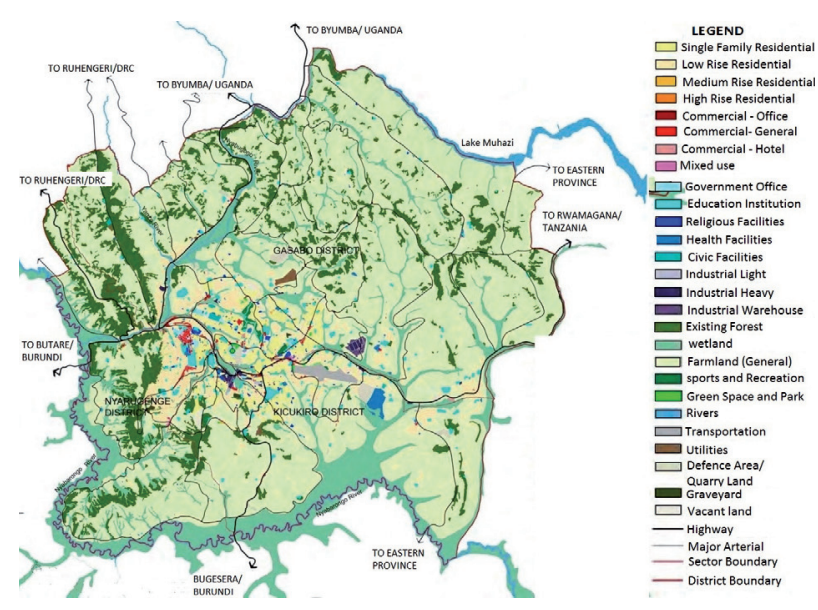

Fig. 2. Existing land use of Kigali city. 

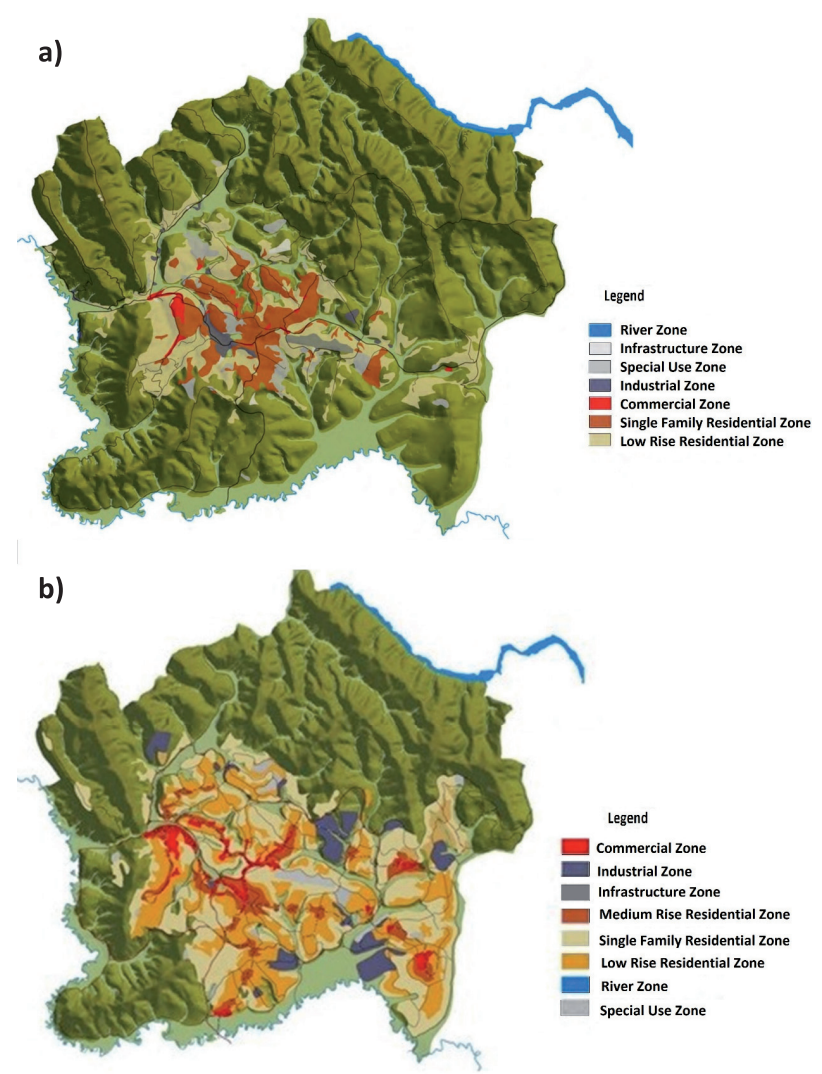

Fig. 3. a) Existing urbanization plan and b) Urbanization plan 2040 [19].

\section{Climate Model}

This study used two GCM-derived scenarios (HadCM3 A2 and B2) to project rainfall. The statistical methodology was adopted for the purpose of downscaling the rainfall at high resolution.

\section{Description of SDSM}

The statistical downscaling model (SDSM) is widely applied to assess local and regional climate change and its impact. It is a combination of the stochastic techniques and multiple regression equations. SDSM uses the empirical statistical process to establish a relationship between the moisture variables in atmosphere (predictors) and locally observed climatic data (predictands) [8]. To develop SDSM, two types of data are needed, including daily time series of NCEP predictors and observed daily time series [20]. The downscaling procedure of the SDSM is performed through a number of steps such as the control of quality, transformation of data, predictor screening, model calibration, weather generator, and validation of the model and generation of future projections [8]. In the application of SDSM, the first step is to determine the occurrence of climate variables (e.g., rainfall) $[9-10,21]$ as follows:

$$
\omega_{i}=\alpha_{o}+\sum_{j=1}^{n} \alpha_{j} \hat{u}_{i}^{(j)}+\alpha_{i-1} \omega_{i-1}
$$

...where $\omega_{i}$ is the candidate in the random process generator that indicates a state of rainfall occurring or not occurring on day $i, \hat{u}_{i}$ is the normalized predictor on day $i$, and $\alpha_{j}$ is the estimated regression coefficient. Precipitation on day i occurs if $\omega_{i} \leq r_{i}$, where $r_{i}$ is a stochastic output from a linear random-number generator. On a wet day, rainfall can be described by:

$$
\mathrm{Z}_{\mathrm{i}}=\beta_{\mathrm{o}}+\sum_{\mathrm{j}=1}^{\mathrm{n}} \beta_{\mathrm{j}} \hat{\mathrm{u}}_{\mathrm{i}}(\mathrm{j})+\varepsilon
$$

$\ldots$ where $Z_{i}$ is the $Z$-score for day $i, \beta_{\mathrm{j}}$ are the estimated regression coefficients for each month, $\varepsilon$ is a normally distributed stochastic error term, and the amount of rainfall $\left(\mathrm{y}_{\mathrm{i}}\right)$ on day i can be simulated as:

$$
\mathrm{y}_{\mathrm{i}}=\mathrm{F}^{-1}\left[\phi\left(\mathrm{Z}_{\mathrm{i}}\right)\right]
$$

... where $\phi$ is the normal cumulative distribution function and $F$ is the empirical distribution function of $y_{i}$.

\section{Predictor Screening}

The predictor screening operation helps to select the suitable downscaling variables. In this study, the screening process started by selecting from different predictors the ones with high explained variance. The same combination applied in Huang et al. (2011) [20] and Mahmood and Babel (2013) [6] of the matrix of correlation and P-value, and partial correlation was successfully applied to this study for assessing the level of correlation of selected predictors.

For this study, 26 available predictors were screened to obtain the suitable variables that could be used together with local precipitation data. For Kigali airport station, the considered data start at 1 January 1961 and end on 31 December 2000, and analysis was annually performed under the conditional process. The potential atmospheric variable $(500 \mathrm{hPa}$ geopotential height and relative humidity at 850 predictors) with high explained variance was selected and used for this study.

\section{SDSM Calibration}

The calibrated downscaling models were constructed based on multiple regression equations between observed climate variables on the local scale and largescale variables supplied by GCMs. The calibration can be done by selecting from among two types of process: unconditional or conditional. The conditional model considers the link between predictands and predictors, whereas the unconditional model takes into account the regional forcing and weather (i.e., occurrence of wet 
and dry days depending on humidity and atmospheric pressure). In conditional models there is an intermediate process between regional forcing and local weather, for example local precipitation amounts depend on the occurrence of wet days which in turn depend on regionalscale predictors such as humidity and atmospheric pressure. In this study, rainfall was set to the conditional model and the daily datasets of 1961-90 were selected for calibration. A monthly sub-model was generated with the NCEP predictors selected during the screening process at Kigali airport station. The performance of the calibration was checked by explained variance (E) and standard error (SE). The same procedure was used in many studies, such as Mahmood and Babel (2013 and 2014) [5-6].

\section{Climate Scenario Generation}

The prediction of future local precipitation was performed by using downscaling techniques. GCMS provide physically based predictions of the way climate might change by taking into account the increasing concentration of atmospheric $\mathrm{CO}_{2}$. In this study, the daily time series of precipitation were projected for three future periods: 1) scenario 2020 stands for 2011 to 2040, 2) scenario 2050 stands for 2041 to 2070 , and 3) scenario 2080 stands for 2071 to 2099 based on the predictors of HadCM3A2 and HadCM3B2 through SDSM.

\section{Downscaling the GCM for Baseline}

This assessment conducted the downscaling process based on observed data from Kigali airport station. The general circulation model was downscaled based on the climatological baseline period of 1961-90 (recommended by IPCC) for A2 and B2 SRES emissions. The downscaled outputs were statistically compared with observed rainfall (Figs 4 and 6).

The outputs of the statistical downscaling model are very close to the observed rainfall in all months, even though there were small differences in individual months (Fig. 4). The outputs of SDSM generally present satisfactory agreements between the observed and downscaled rainfall during calibration for all months. The small model errors appearing in the different months were observed. However, the findings can be considered as satisfactory due to the reality that rainfall downscaling is absolutely more problematic than other variables

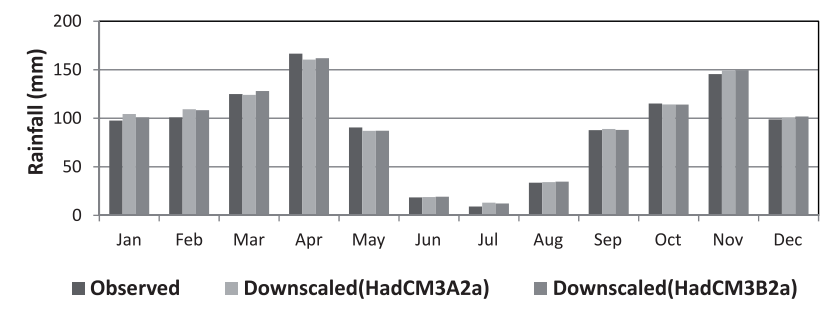

Fig. 4. Observed and downscaled rainfall for baseline period (1960-1990). (e.g., temperature), since daily precipitation data at the local station are relatively poorly resolved by regionalscale predictors. There is a high correlation between monthly rainfall of the Nyabugogo catchment and the downscaled rainfall supplied by using the GCMS model with a correlation coefficient R of 0.9161 and 0.9126 , respectively, for $\mathrm{A} 2$ and $\mathrm{B} 2$ emissions (Fig. 5).

\section{Flood Frequency Analysis}

During this assessment, the frequency analysis method was used as an aid to obtain a return period of the extreme rainfall events. Flood risk differs over time as a consequence of climate variability and climate change factors. Different developed scenarios (2020s, 2050s, and 2080s) have been applied for this objective by applying the predictors from NCEP and HadCM3. Flood frequency analysis reflects the effects of projection of greenhouse
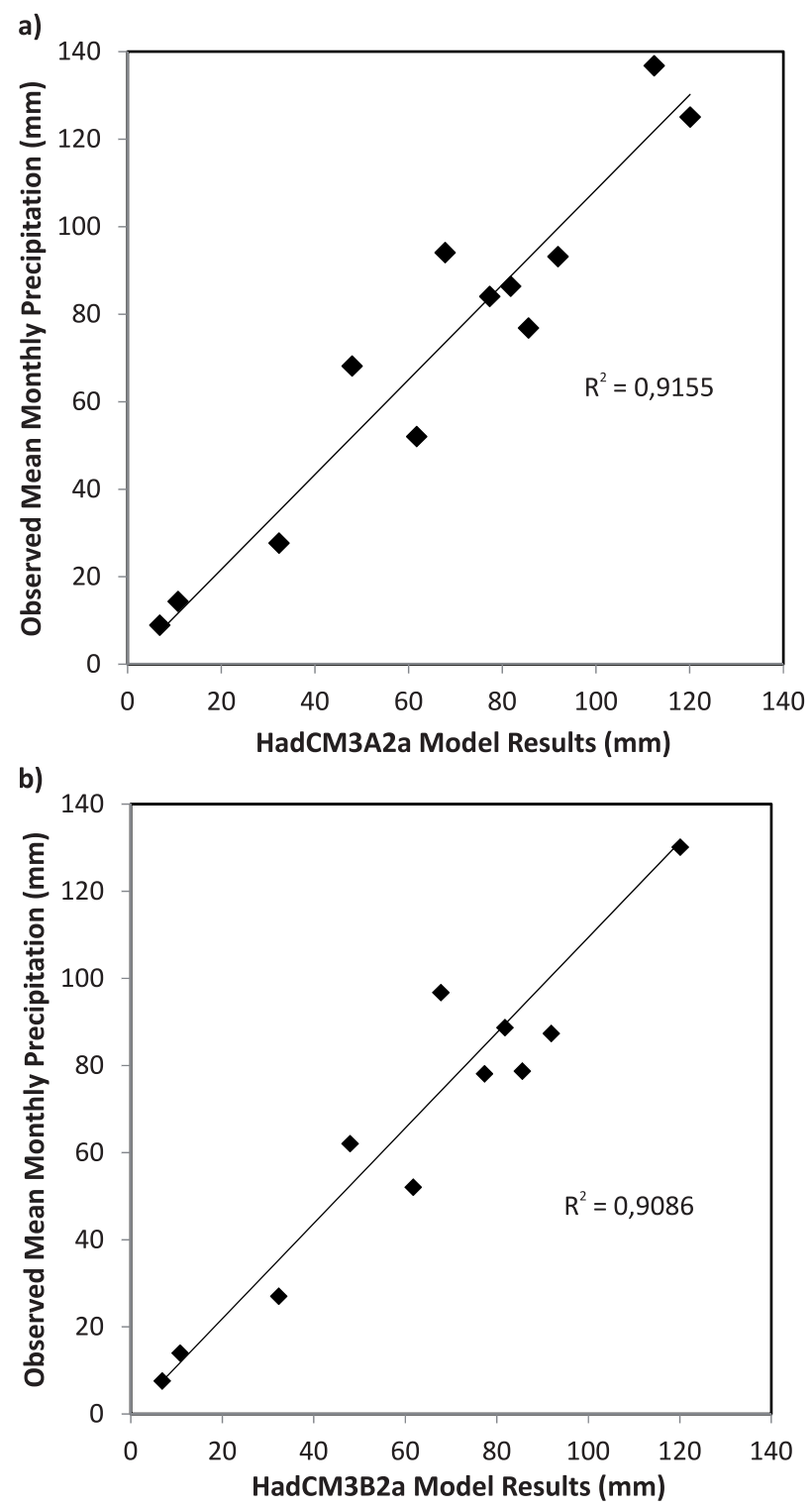

Fig. 5. Correlation between observed and downscaled monthly rainfall for $\mathrm{A} 2$ and $\mathrm{B} 2$ emission scenarios. 
gas increases in the atmosphere in terms of the change of the event quantity. Through SDSM, the cumulative distributions were developed to find the return periods of maximum rainfall events in Kigali.

\section{Hydrological Model}

For this study, the latest version of HEC-HMS and HEC-GeoHMS [22] (geospatial hydrological modeling extension) together with ArcGIS [23] were adopted to simulate the rainfall-runoff and delineate the Nyabugogo watershed in order to generate the basin characteristics (area, reach length, slopes, etc). The HEC-HMS is a reliable model developed by the U.S. Army Corps of Engineers that could be used for many hydrological simulations [24]. It is designed to be applicable in a wide range of geographical areas for solving the widest possible range of issues, such as supplying of water, flooding, and basin runoff.

\section{The Curve Numbers Generation}

The average curve numbers for the Nyabugogo subcatchment were calculated through ArcGIS 10.2 (Figure 6) by applying a combination of land cover, soil data, and DEM of the Nyabugogo catchment through ArcGIS. To perform this task in this study required three shape-files: 1) the drainage watershed boundaries for which curve number(s) were determined, 2) the land use map, and 3) the soil-type map. The lookup table was defined according to the SCS TR 55 report of 1986 (Table 2). This table contains two main parts: the first describes the conversion from soil types to hydrologic soil groups while the second provides the curve number table that defines the land usesoil group categories and curve numbers (Table 2). The A, B, C, and D soil types stand for hydrologic soil groups and their differences depend on infiltration rate. They possess respectively high, moderate, slow, and very slow infiltration rates. The curve number grid was created in Arc Map through the union possessing attributes combined to hydroDEM, land use polygon, soil feature class, and the CN lookup-table.

\section{Computation Methods in HEC-HMS}

The loss method: In this assessment, the determination of the distribution of rainfall into infiltration and runoff was the first step to create the output hydrograph. The

Table 2. Curve number lookup table [21].

\begin{tabular}{|c|c|c|c|c|}
\hline Land use description & A & B & C & D \\
\hline Water bodies & 100 & 100 & 100 & 100 \\
\hline Medium residential & 57 & 72 & 81 & 86 \\
\hline Forest & 30 & 58 & 71 & 78 \\
\hline Agriculture & 67 & 77 & 83 & 87 \\
\hline
\end{tabular}

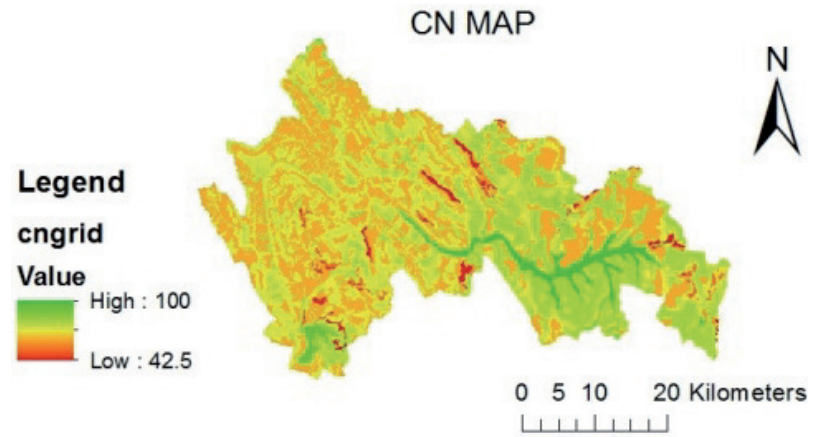

Fig. 6. The curve number for currents case of Nyabugogo watershed generated using ArcGIS.

SCS curve number method was chosen for quantifying base flow, surface runoff, and actual evaporation. The SCS curve number allows the rainfall to be partitioned into the two components of infiltration: ET losses and runoff. The curve numbers represent the degree of rainfall that will be converted into direct runoff, i.e., the higher the curve number, the more runoff. In the SCS method, initial abstraction is generally assumed to be $20 \%$ of maximum potential retention:

$$
\mathrm{I}_{\mathrm{a}}=0.2 * \mathrm{~S}
$$

...where $\mathrm{S}$ is defined as maximum potential retention calculated from (Eq.5) using the curve number as:

$$
S=\frac{25400}{C N}-254
$$

... and the cumulative excess rainfall (runoff) is given by (Eq. 6):

$$
Q=\frac{(P-0.2 S)^{2}}{P+0.8 S}
$$

...where P stands for total rainfall (mm) for the storm event or for daily rainfall.

The transform method allows converting the runoff value obtained from Eq. 6 into a physical hydrograph. In this study the Soil Conservation Service (SCS) unit hydrograph was selected for modeling in HEC-HMS. The runoff produced from the loss calculation was converted into an outflow hydrograph. The general hydrograph takes the time lag from each sub-basin and scales the outflow for using in the unit hydrograph [13]. The time lag was calculated in ArcGIS by using HEC-GeoHMS extension tools and curve number $(\mathrm{CN})$ method. The lag time and concentration time were given by a relation presented in (Eq. 7):

$$
\mathrm{T}_{\mathrm{lag}}=0.6 * \mathrm{~T}_{\mathrm{C}}
$$




$$
\mathrm{T}_{\mathrm{C}}=\frac{\mathrm{L}^{0.8} *(\mathrm{~S}+25.4)^{0.7}}{4238 * \mathrm{Y}^{0.5}}
$$

... where $\mathrm{T}_{\text {lag }}$ is the lag time (hours), $\mathrm{T}_{\mathrm{c}}$ is time of concentration (hours), L is longest flow path (m), $\mathrm{Y}$ is basin slope (\%), and $\mathrm{S}$ is the maximum possible retention that can be calculated using Eq. 5 .

Baseflow method: The baseflow method simulates the response of the infiltrated water back into the stream network. In this study, the recession method during this assessment was selected for modeling the infiltration. The recession method uses a single exponential equation (Eq. 9) that relates the initial baseflow and the baseflow at time $t$. This method also requires a value that will indicate when baseflow resumes the full flow in an element; this was done using the ratio-to-peak method. A ratio-to-peak of $1 \%$ was chosen for modeling in this study:

$$
\mathrm{Q}_{\mathrm{t}}=\mathrm{Q}_{\mathrm{o}} \mathrm{K}^{\mathrm{t}}
$$

... where $\mathrm{Q}_{t}$ is the baseflow, $\mathrm{Q}_{\mathrm{O}}$ is the initial discharge, $\mathrm{k}$ is the recession constant, and $t$ stands for time.

Routing method: Once all of the basin parameters converting the rainfall into runoff have been calculated, the hydrographs need to be moved downstream through the stream network. This is done through routing methods in HEC-HMS. There are six routing methods built into HMS. In this study, since there are no gauges or historical data available to calibrate to, the most convenient routing method available for use was a storage discharge relationship (Eq. 10) that defines how water will be attenuated through the reach using conservation of mass [13]:

$$
\left(\frac{\mathrm{S}_{\mathrm{t}}}{\Delta \mathrm{t}}+\frac{\mathrm{Q}_{\mathrm{t}}}{2}\right)=\left(\frac{\mathrm{I}_{\mathrm{t}-1}+\mathrm{I}_{\mathrm{t}}}{2}\right)+\left(\frac{\mathrm{S}_{\mathrm{t}-1}}{\Delta \mathrm{t}}-\frac{\mathrm{Q}_{\mathrm{t}-1}}{2}\right)
$$

...where $S_{t, t-1}$ is the storage at time $t ; t-1, I_{t}, t$ are inflow discharge at times $t$ and $t-1 ; Q_{t, t-1}$ is the outflow discharge at times $\mathrm{t}$ and $\mathrm{t}-1$; and $\Delta \mathrm{t}$ is the simulation time step.

\section{Creation of Design Storms}

Hydrologic model simulations were performed by following the return periods (T) $2,10,25,50$, and 100 years, corresponding to $50,10,4,2$, and 1 percent exceedance probabilities $(p=1 / T)$. In this study, the design storms were created through HEC-HMS. The main input data for the frequency-based design storm (Table 3) with a specified return period were: total storm duration, rainfall depths for a number of given durations within the total storm duration, the position of the highest intensity within the storm, and the storm area. Based on these input parameters, HEC-HMS uses the alternating block method to compute the design hyetograph that was applied during the simulation.
Table 3. Kigali's IDF curve values for frequency storm design (mm/day).

\begin{tabular}{|c|c|c|c|c|c|c|}
\hline & $\begin{array}{c}2 \\
\text { Years }\end{array}$ & $\begin{array}{c}5 \\
\text { Years }\end{array}$ & $\begin{array}{c}10 \\
\text { Years }\end{array}$ & $\begin{array}{c}20 \\
\text { Years }\end{array}$ & $\begin{array}{c}50 \\
\text { years }\end{array}$ & $\begin{array}{c}100 \\
\text { Years }\end{array}$ \\
\hline $\begin{array}{c}15 \\
\text { Min }\end{array}$ & 20.8 & 24 & 26.1 & 28.1 & 30.7 & 40.2 \\
\hline $\begin{array}{c}30 \\
\text { Min }\end{array}$ & 28.2 & 32.5 & 35.3 & 38.1 & 41.6 & 54.5 \\
\hline $\begin{array}{c}45 \\
\text { Min }\end{array}$ & 32.1 & 37 & 40.3 & 43.4 & 47.4 & 62.1 \\
\hline $\begin{array}{c}1 \\
\text { Hour }\end{array}$ & 35.1 & 39.9 & 43.4 & 46.8 & 51.1 & 68.7 \\
\hline $\begin{array}{c}2 \\
\text { Hour }\end{array}$ & 50.1 & 57.8 & 62.8 & 67.7 & 74 & 97.0 \\
\hline $\begin{array}{c}3 \\
\text { Hour }\end{array}$ & 65.6 & 76.7 & 83.3 & 89.8 & 98.2 & 129.3 \\
\hline
\end{tabular}

\section{Results and Discussion}

\section{Climate Model Results for Precipitation}

In this study, the time series of rainfall were developed in a statistical downscaling model together with the global circulation model's variables under two emission scenarios (A2 and B2) for future years. This study has considered the three interval periods of 30 years for each of them: 2020 scenario, 2050 scenario, and the 2080 scenario. The downscaled results were compared to the baseline data within the period of 1961-90 as recommended by the IPCC to analyze the global warming effects and climate change influence on rainfall at Nyabugogo catchment.

The results presented in Figs $7 \mathrm{a}$ and $7 \mathrm{~b}$ show the percentage differences of considered scenarios of the periods: $2011-40,2041-70$, and 2071-99 proportionally to the baseline of 1961-90. They are the differences of downscaled rainfall for the baseline period and the future climate change model outputs.

The floods in Kigali occur in the rainy season from April to June and from September to December. Regarding the results of A2, the highest increase in rainfall is expected in June to be $30.2 \%$ for scenario 2020 and $27 \%$ for scenario 2070 in May, and in November 23.6\% of the increase is estimated for scenario 2070. Based on the $\mathrm{B} 2$ pattern, it is predicted that the rainfall will increase by $23 \%$ in May during $2011-40$ and $41.1 \%$ during 2071-40. The precipitation pattern of Kigali will be affected by climate change and an increase of extreme rainfall events is likely to happen in the rainy season, which in turn will affect the flood hydrograph of the city.

The overall results of downscaled monthly rainfall did not present a regular change pattern (rise or decline) for the considered scenarios for A2 and B2 SRES emissions (Figs $7 \mathrm{a}$ and $7 \mathrm{~b}$ ). In general, a decrease of total annual rainfall of $0.2 \%$ and $5.9 \%$ is expected for 2020 s under $\mathrm{A} 2$ and $\mathrm{B} 2$, respectively. A decrease of $4.4 \%$ and an increase of $1.08 \%$ are likely to happen for 2050 s under A2 and B2 

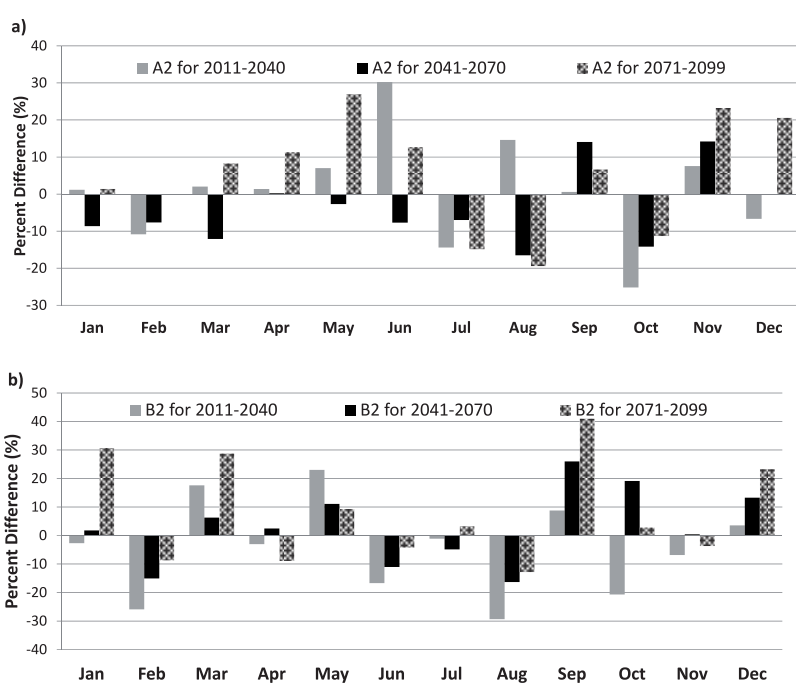

Fig. 7. Rainfall Percentage Difference from base line: 1961-1990 a) for Scenario A2 and b) for Scenario B2

emissions, respectively, and for 2080s annual rainfall will be increased by $4.51 \%$ and $7 \%$ for $\mathrm{A} 2$ and $\mathrm{B} 2$, respectively.

\section{Rainfall Frequency Analysis}

The cumulative distribution graphs have been generated to show the return periods of extreme rainfall events. Relative to the baseline period 1961-90, increasing in return periods for daily maximum rainfall is obvious for the period of 2011-40 (Figs 8a and 8b). No considerable change was detected for the 2041-70 and 2071-99 scenarios,. The significant increase in daily precipitation extreme was observed in the 2011-40 scenario for both A2 and $\mathrm{B} 2$ patterns with maximum rainfall of $55.67 \mathrm{~m}^{3} \cdot \mathrm{s}^{-1}$ and $56.88 \mathrm{~m}^{3} \cdot \mathrm{s}^{-1}$, respectively (Figs $8 \mathrm{a}$ and $8 \mathrm{~b}$ ).

\section{Hydrological Model Results}

The HEC-HMS model was used to simulate the expected flood of hydrographs by considering four different cases: 1) without considering climate and land use change impact (current case), 2) by considering only the climate change impact, 3 ) by considering the land use change impact only, and 4) by considering both the climate and land use change impact simultaneously. The current case peak flood discharges are calculated by rainfall intensities obtained from IDF curves generated for Kigali.

Hydrographs without considering the climate and land use change impact as the current case are presented in Fig. 9a. It was found that a two-year storm leads to peak discharge of $10.6 \mathrm{~m}^{3} \cdot \mathrm{s}^{-1}$, whereas a five-year storm leads to a peak discharge of $16.5 \mathrm{~m}^{3} \cdot \mathrm{s}^{-1}$. The peak flow continues to increase in the return periods of 10,25 , and 50 years with values of $21.4,26.9$, and $35.1 \mathrm{~m}^{3} \cdot \mathrm{s}^{-1}$, respectively. The highest peak flow was noted for a 100 -year storm with a peak value of $73.4 \mathrm{~m}^{3} \cdot \mathrm{s}^{-1}$.

Fig. 9b takes into account increased urbanization only in terms of impervious areas. The increase of
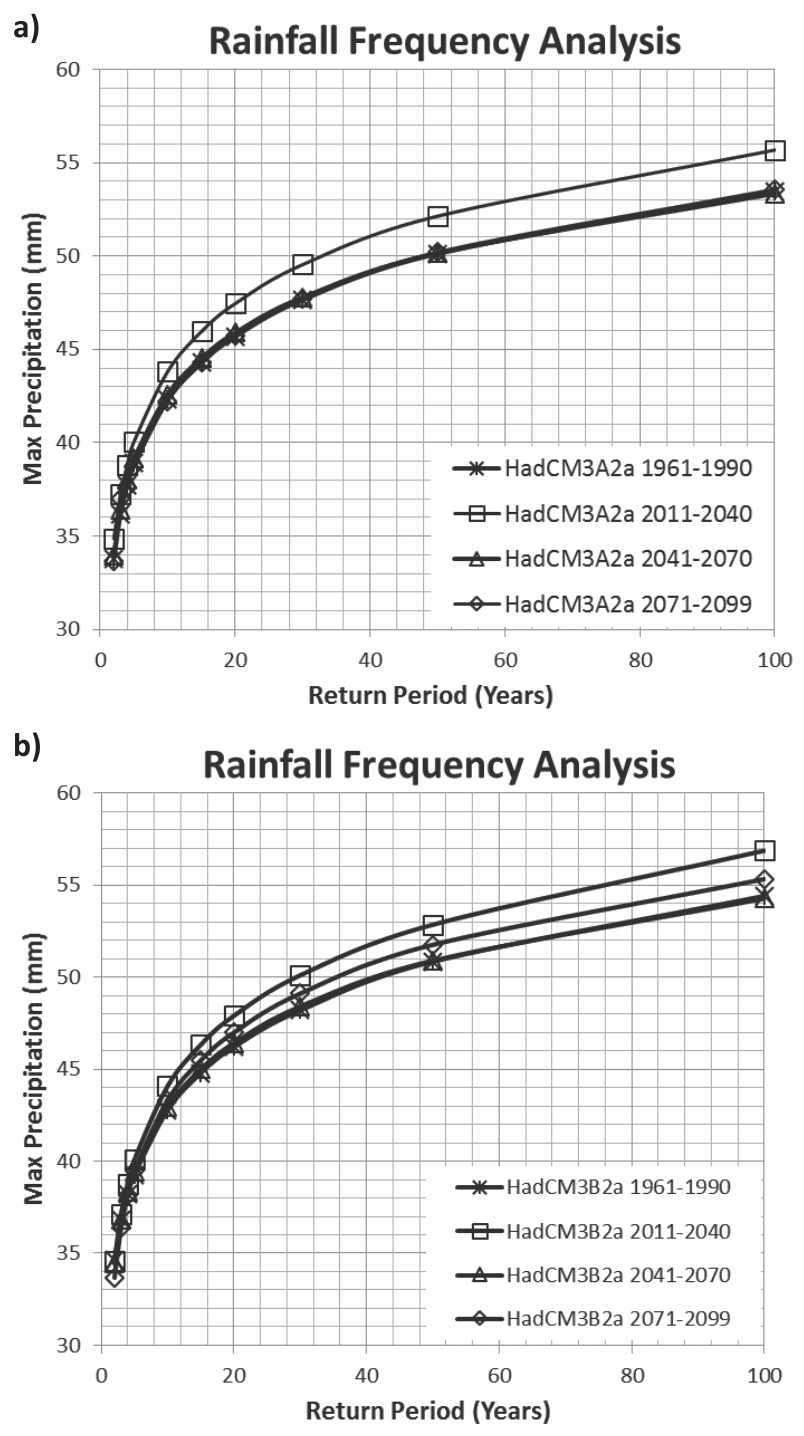

Fig. 8. Cumulative distributions of maximum values of rainfall for a) HadCM3A2 and b) HadCM3B2 scenarios.

hydrographs for land use change is obvious and the flood peak is higher. It was found that the two-year storm leads to a peak discharge of $18.3 \mathrm{~m}^{3} / \mathrm{sand}$ the five-year storm reaches a peak flow of $25.2 \mathrm{~m}^{3} \cdot \mathrm{s}^{-1}$. The increase of flood peak discharge continues to be noted with the return period of 10,25 , and 50 years with values of $30.8,36.9$, and $45.8 \mathrm{~m}^{3} \cdot \mathrm{s}^{1}$, respectively. The highest peak discharge was observed in a 100-year storm with peak value of 86.6 $\mathrm{m}^{3} \cdot \mathrm{s}^{-1}$. Kigali's growth will generate an overall increase in impervious area from of $17 \%$ (currently) to $51 \%$ of builtup areas $(43 \%$ of residential, $5 \%$ industrial zones, and 3\% ocommercial) in 2040 as stated by the Kigali master plan. This will produce extreme flooding due to the fact that the infiltration rate will be reduced.

Fig. 10 a) takes into consideration the climate change impact. According to scenarios A2 and B2, the study area will experience higher temperatures and consequently higher evapotranspirations and lower annual precipitation, and both scenarios reduce expected flood discharges. Annual rainfalls are expected to decrease $0.2 \%$ and $5.9 \%$ 
a)

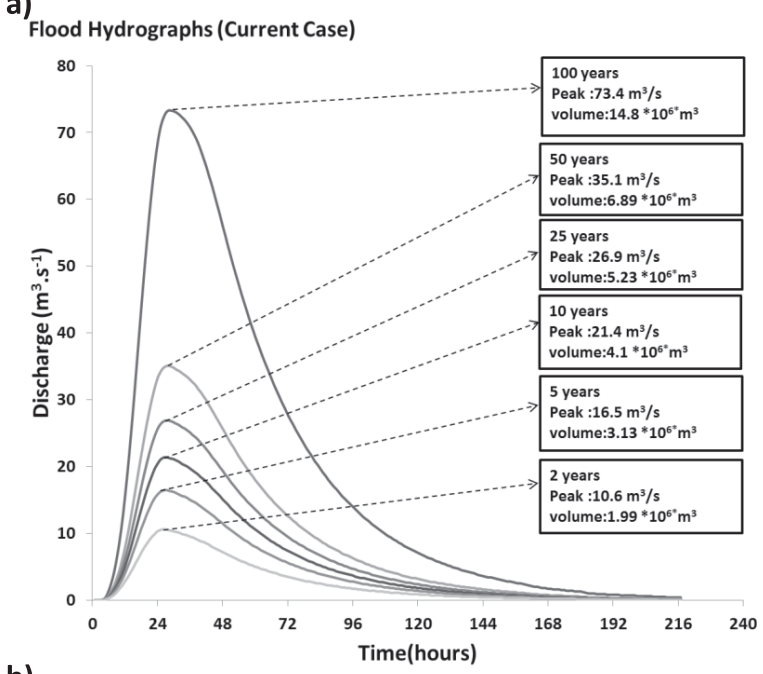

b)

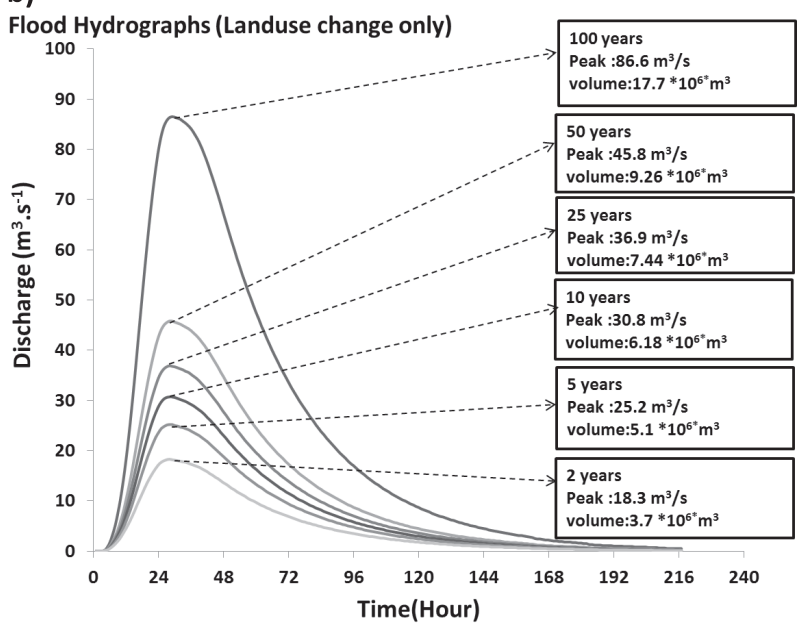

Fig. 9. Flood hydrographs: a) without considering climate and land use change impact (current case obtained by using IDF curves of Kigali city), b) with land use change only.

for $2020 \mathrm{~s}$, to be decreased $4.4 \%$ and increased $1.08 \%$ for $2050 \mathrm{~s}$, and to be increased by $4.51 \%$ and $7 \%$ for $2070 \mathrm{~s}$ for A2 and B2 scenarios, respectively. Expected flood discharges for future periods are calculated using intensity versus return period graphics obtained from SDSM models, but the flood discharges for the current case are obtained by using IDF curves generated for Kigali (Table 3). Therefore, flood discharges calculated for scenarios A2 and B2 for climate change only are lower than the current case. For the A2 pattern, the two-year storm leads to a peak discharge of $7.3 \mathrm{~m}^{3} \cdot \mathrm{s}^{-1}$, a five-year storm leads to a peak discharge of $11.3 \mathrm{~m}^{3} \cdot \mathrm{s}^{-1}$, and for the $10-, 25-$, and 50-year storms the peak flows will reach $14.1,19.8$, and $24.5 \mathrm{~m}^{3} \bullet \mathrm{s}^{-1}$, respectively. The highest Peak discharge value can be seen in a 100-year storm with peak discharge of $29.6 \mathrm{~m}^{3} \cdot \mathrm{s}^{-1}$. For the B2 pattern (Fig. 10b), the two-year storm leads to a peak discharge of $7.9 \mathrm{~m}^{3} \cdot \mathrm{s}^{-1}$, a five-year storm leads to a peak discharge of $10.8 \mathrm{~m}^{3} \cdot \mathrm{s}^{-1}$, and for $10-, 25$-, and 50 -years storms the a)

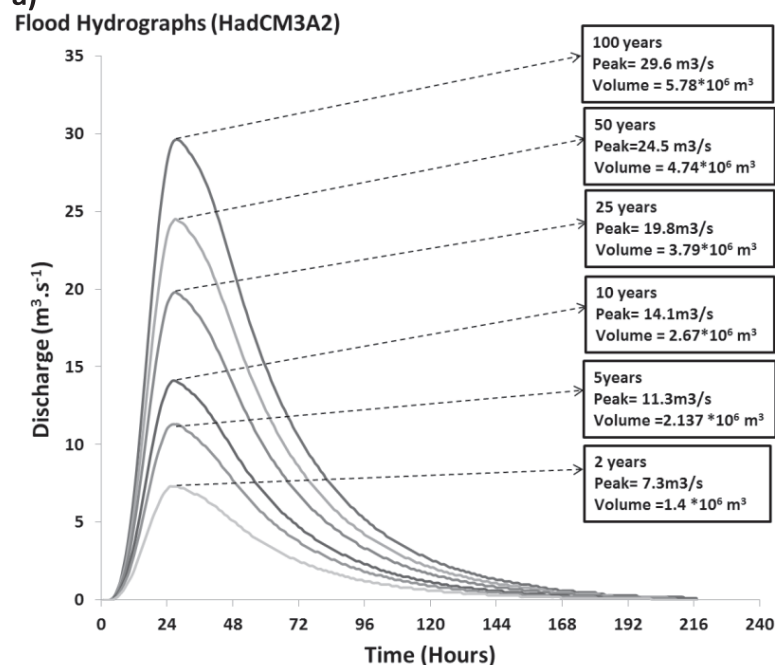

b)

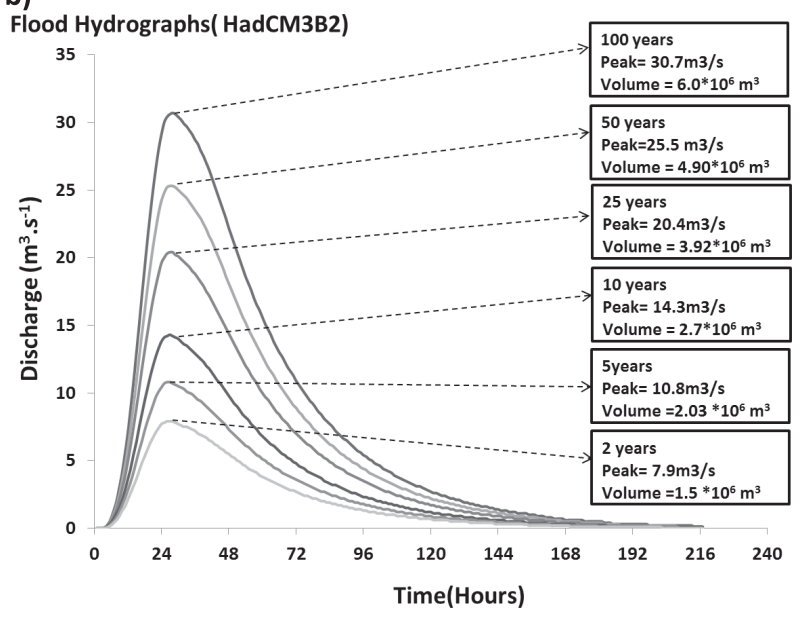

Fig. 10. Flood hydrographs considering climate change impact a) for scenario $\mathrm{A} 2$ and b) for scenario $\mathrm{B} 2$.

peak flow reaches $14.3,20.4$, and $25.4 \mathrm{~m}^{3} \bullet \mathrm{s}^{-1}$, respectively. The peak discharge of $30.7 \mathrm{~m}^{3} \cdot \mathrm{s}^{-1}$ is noted for the 100 -year storm.

Figs 11 a, b) present the flood hydrographs by combining the climate and land use change impact. For A2 emissions, the two-year storm leads to a peak discharge of $14.1 \mathrm{~m}^{3} \cdot \mathrm{s}^{-1}$, the five-year storm leads to a peak discharge of $19.2 \mathrm{~m}^{3} \cdot \mathrm{s}^{-1}$, and the peak discharges for 10-, 25-, and 50-year storms reach 22.5, 29.0, and $34.3 \mathrm{~m}^{3} \cdot \mathrm{s}^{-1}$, respectively. The highest Peak discharge value was found for the 100-year storm with peak discharge of $39.9 \mathrm{~m}^{3} \cdot \mathrm{s}^{-1}$. B2 emissions for the two-year storm lead to a peak discharge of $14.9 \mathrm{~m}^{3} \cdot \mathrm{s}^{-1}$, and the five-year storm leads to a peak discharge of $18.5 \mathrm{~m}^{3} \cdot \mathrm{s}^{-1}$. The peak discharge for the 10-, 25-, and 50-year storms reach 22.7, 29.7, and $35.2 \mathrm{~m}^{3} \cdot \mathrm{s}^{-1}$, respectively. A peak discharge of $41.1 \mathrm{~m}^{3} \cdot \mathrm{s}^{-1}$ is observed for the 100-year storm. All flood peak discharges for current and future climate and land use change are presented in Table 4. 
a)
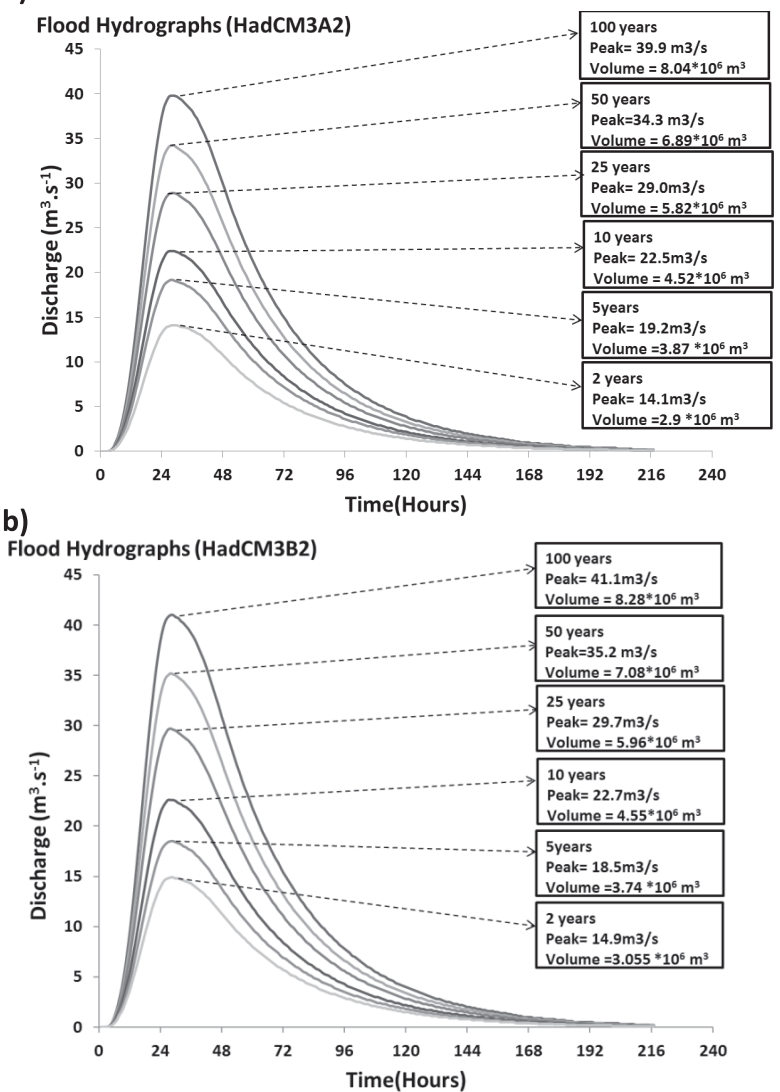

Fig. 11. Flood hydrographs considering climate and land use change impact (Emission A2 and B2)

\section{Conclusions}

This study might be helpful for supporting decisionmakers in Kigali to deal with the consequences of climate change and urbanization that contribute to the flooding of the Nyabugogo River. During this study we used the statistical downscaling model (SDSM) to better explore the future change in precipitation in the Nyabugogo watershed under the IPCC SRES A2 and B2 emissions for the future periods of 2011-40, 2014-70, and 2071-99 relative to the baseline period of 1961-90.

The projected rainfall illustrates neither the regular increase nor decrease for the next 100 years for the A2 and B2 patterns. However, there is an increase of monthly rainfall during the rainy season where floods occur in Kigali. The total annual rainfall will decrease by $0.2 \%$ and $5.9 \%$ in the 2020 s for A2 and B2 patterns, respectively. A decrease of $4.4 \%$ and an increase of $1.08 \%$ are more likely to happen for 2050s in respect to A2 and B2 than for 2080 scenario, in which annual rainfall will increase by $4.51 \%$ and $7 \%$ for $\mathrm{A} 2$ and $\mathrm{B} 2$, respectively. The occurrence of the maximum daily rainfall event of $56.88 \mathrm{~m}^{3} \bullet \mathrm{s}^{-1}$ is expected to happen during the interval period of 2011-40.

In this research the HEC-HMS model was used for the Nyabugogo watershed. The model performed reasonably well in producing the flood hydrographs. The results revealed that climate change will have a significant impact in decreasing the peak discharge of expected hydrographs in the current case condition (without climate and land use change) for all considered return periods of storms, whereas the land use change has shown a considerable increase of expected discharge peaks and volumes. The combination of climate and land use change study also has shown an increase of flood peak discharge of expected hydrographs for $2,5,10$, and 25 years of the return period, whereas there is a decrease for 50 and 100 years of the return period. Runoff generated from the frequency storm method will be extremely useful for future flood hazards and risk assessment studies in the Nyabugogo catchment. The results show that the land use change will affect the hydrologic processes of the watershed by increasing the amount of surface runoff, which will lead to severe flooding in Kigali.

\section{Acknowledgements}

This research is part of a master of science study carried out at Y1ldız Technical University in Turkey. The authors would first like to thank Turkey for supporting this study by providing scholarship to the master student of this study who is from Rwanda. Secondly, our thanks

Table 4. Summary of the results for flood peak discharges for current case and expected land use and climate change scenarios.

\begin{tabular}{|c|c|c|c|c|c|c|}
\hline \multirow{2}{*}{$\begin{array}{c}\text { Return periods } \\
(\text { Years })\end{array}$} & $\begin{array}{c}\text { Current case } \\
\left(\mathrm{m}^{3} \cdot \mathrm{s}^{-1}\right)\end{array}$ & \multicolumn{2}{|c|}{$\begin{array}{c}\text { Impact of land use } \\
\text { change } \\
\left(\mathrm{m}^{3} \cdot \mathrm{s}^{-1}\right)\end{array}$} & \multicolumn{2}{|c|}{ Impact of climate change only } & \multicolumn{2}{|c|}{$\begin{array}{c}\text { Combined impact of climate and land } \\
\text { use change }\end{array}$} \\
\cline { 4 - 7 } & 18.3 & $\begin{array}{c}\text { A2 Scenarios } \\
\left(\mathrm{m}^{3} \cdot \mathrm{s}^{-1}\right)\end{array}$ & $\begin{array}{c}\text { B2 Scenarios } \\
\left(\mathrm{m}^{3} \cdot \mathrm{s}^{-1}\right)\end{array}$ & $\begin{array}{c}\text { A2 Scenarios } \\
\left(\mathrm{m}^{3} \cdot \mathrm{s}^{-1}\right)\end{array}$ & $\begin{array}{c}\text { B2 Scenarios } \\
\left(\mathrm{m}^{3} \cdot \mathrm{s}^{-1}\right)\end{array}$ \\
\hline 2 & 10.6 & 7.3 & 7.9 & 14.1 & 14.9 \\
\hline 5 & 16.5 & 25.2 & 11.3 & 10.8 & 19.2 & 18.5 \\
\hline 10 & 21.4 & 30.8 & 19.8 & 20.4 & 29 & 22.7 \\
\hline 25 & 26.9 & 36.9 & 24.5 & 25.4 & 34.3 & 29.7 \\
\hline 50 & 35.1 & 45.8 & 29.6 & 30.7 & 39.9 & 35.1 \\
\hline 100 & 73.4 & 86.6 & & & & 41.1 \\
\hline
\end{tabular}


to the Rwanda Meteorological Department for providing climate data used in this study. The authors also appreciate the developers of the HEC-HMS and SDSM models for providing them free of charge.

\section{References}

1. MOLAVI S., MUTTIL N., TRAN H.D. Urban flood modeling and climate change: a Melbourne area case study. $19^{\text {th }}$ International Congress on Modeling and Simulation, Perthş Australiaş, 2011.

2. MAILHOT A., DUCHESNE S. Design criteria of urban drainage infrastructures under climate change. J. Water Resour. Plann. Manage 136, 201, 2010.

3. IPCC summary for policymakers. in: climate change 2013: The physical science basis. contribution of working group I to the fifth assessment report of the intergovernmental panel on climate change.cambridge university press, cambridge, united kingdom and New York, NY, USA, 2013.

4. IPCC reportclimate changethe physical science basis, contribution of working group I to the fourth assessment report of the intergovernmental panel on climate change, cambridge university press. Cambridge, 2007.

5. MAHMOOD R., BABEL M. Future changes in extreme temperature events using the statistical downscaling model (SDSM) in the trans-boundary region of the Jhelum river basin. Weather Clim. Extremes. 5 (6), 56, 2014.

6. MAHMOOD R., BABEL M. Evaluation of SDSM developed by annual and monthly sub-models for downscaling temperature and precipitation in Jhelumbasin, Pakistan and India. Theor. Appl.climatol. 113 (1-2), 27, 2013.

7. XU C.Y. Climate change and hydrological models: a review of existing gaps and recent research developments. WaterResour. Manag.13 (5), 369, 1999.

8. WILBY R.L, DAWSON C.W, BARROW E.M. SDSM- a decision support tool for the assessment of regional climate change impacts. Environ. Modell. Software. 17 (2), 145, 2002.

9. CHU J., XIA J., XU C.Y.,SINGH V. Statistical downscaling of daily mean temperature, pan evaporation and precipitation for climatechange scenarios in Haine river, China. Appl. Climatol. 99 (1), 149, 2010.

10. WANG X.Y., YANG T., SHAO Q.X., ACHARYA K., WANG W.G, YU Z.B. Statistical downscaling of extremes of precipitation and temperature and construction of their future scenarios in an elevated and cold zone, Hydrol.Processes. 26 (3), 405, 2012.

11. GEBREMESKEL S., LIU Y.B, SMED F.L, HOFFMANN P. Analyzing the effect of climate changes on streamflow using statistically downscaled GCM Scenarios.Int. J. River Basin Manage. 2 (4), 271, 2005.

12. CHENG C.S, AULD H., LI Q.,AND LI G.L.Possible impacts of climate change on extreme weather events at local lcale in South-central Canada. Clim. Change. 112 (3-4), 963, 2012.

13. SCHARFFENBERG W., FLEMING M. Hydrologic modeling system HEC-HMS v3.2 user's manual, USACEHEC, Davis, USA, 2010.

14. YENER M.K, SORMAN A.Ü., SORMAN A.A, GEZGIN T. Modeling studies with HEC-HMS and runoff scenarios in yuvacik basin. Int. Congr.River Basin Manage 4, 621, 2007 [In Turkey].

15. CHU X., STEINMANA.D. Event and continuous hydrologic modeling with HEC-HMS. Irrig. Drain. Eng. 135, 119, 2009.

16. MUNYANEZA O., MUKUBWA A., MASKEY S., UHLENBROOK S., WENNINGER J. Assessment of surface water resources availability using catchment modelling and the results of tracer studies in the mesoscale Migina catchment, Rwanda. Hydrol. Earth Syst. 18, 5289, 2014.

17. Canadian Institute for Climate Studies (CICS). http://www. cics.uvic.ca/scenarios/sdsm/select.cgi

18. CCCSN. Statistical downscaling input; HadCM3 Predictors: A2 and B2 Experiments, 2012. http://www.ccesn.ec.gc. ca/?page=pred-hadcm 3

19. SURBANA. Detailed Kigali city master plan, Rwanda: Vision report, Kigali, May, 2012.

20. HUANG J., ZHANG J., ZHANG Z., XU C., WANG B., YAO J. Estimation of future precipitation change in the Yangtze river basin by using statistical downscaling method, Stoch. Environ. Res. RiskA. 25 (6), 781, 2011

21. WETTERHALL F., BÁRDOSSY A., CHEN D., HALLDIN S., XU C.Y. Statistical downscaling of daily precipitation over Sweden using GCM output. Theor Appl Climatol. 96 (1), 95, 2009.

22. FLEMING M.J., DOAN J.H. HEC-GeoHMS Geospatial Hydrologic Modeling Extension. Davis: United States Army Corps of Engineering, USA, 2010.

23. ESRI. ArcGIS Desktop: Release 10 Redlands, CA: Environmental System Research Institute, USA, 2011.

24. HALWATURA D., NAJIM M. Application of the HECHMS model for runoff simulation in a tropical catchment. Environmental Modeling \& Software. 46, 155, 2013. 
